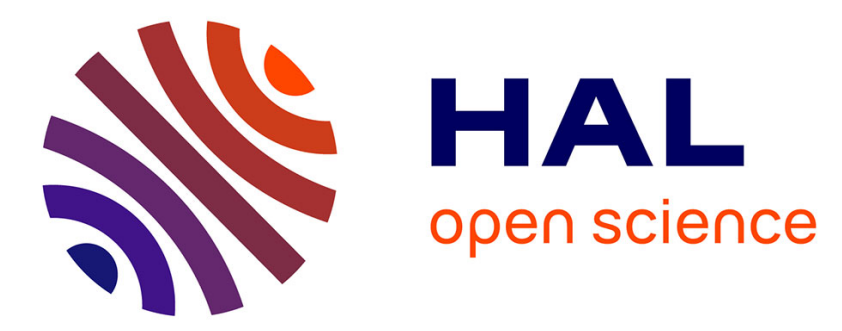

\title{
Simulation and experimental validation of a Hydrogen storage tank with Metal Hydrides
}

Maxime Botzung, Serge Chaudourne, Olivier Gilla, Christian Perret, Michel Latroche, Annick Percheron-Guegan, Philippe Marty

\section{- To cite this version:}

Maxime Botzung, Serge Chaudourne, Olivier Gilla, Christian Perret, Michel Latroche, et al.. Simulation and experimental validation of a Hydrogen storage tank with Metal Hydrides. International Journal of Hydrogen Energy, 2008, 33 (issu 1), pp.98-104. 10.1016/j.ijhydene.2007.08.030 . hal00266690

\section{HAL Id: hal-00266690 \\ https://hal.science/hal-00266690}

Submitted on 4 Feb 2020

HAL is a multi-disciplinary open access archive for the deposit and dissemination of scientific research documents, whether they are published or not. The documents may come from teaching and research institutions in France or abroad, or from public or private research centers.
L'archive ouverte pluridisciplinaire HAL, est destinée au dépôt et à la diffusion de documents scientifiques de niveau recherche, publiés ou non, émanant des établissements d'enseignement et de recherche français ou étrangers, des laboratoires publics ou privés. 


\title{
Simulation and experimental validation of a hydrogen storage tank with metal hydrides
}

\author{
Maxime Botzung ${ }^{\mathrm{a}, *}$, Serge Chaudourne ${ }^{\mathrm{a}}$, Olivier Gillia ${ }^{\mathrm{a}}$, Christian Perret ${ }^{\mathrm{a}}$, Michel Latroche $^{\mathrm{b}}$, \\ Annick Percheron-Guegan ${ }^{\mathrm{b}}$, Philippe Marty ${ }^{\mathrm{c}}$ \\ ${ }^{\text {a } C E A ~ G r e n o b l e, ~ D R T / L I T E N / D T H, ~} 17$ rue des Martyrs, 38054 Grenoble, Cedex \\ ${ }^{\mathrm{b}}$ CNRS, CMTR-ICMPE-UMR7182, 2-8 rue Henri Dunant, 94320 Thiais Cedex, France \\ ${ }^{\mathrm{c}}$ CEA, Equipe LEGI-GRETh, 17 rue des Martyrs, 38054 Grenoble Cedex, France
}

This paper presents a hydrogen storage system using metal hydrides for a combined heat and power (CHP) system. Hydride storage technology has been chosen due to project specifications: high volumetric capacity, low pressures $(<3.5$ bar $)$ and low temperatures $\left(<75^{\circ} \mathrm{C}\right.$ : fuel cell temperature).

During absorption, heat from hydride generation is dissipated by fluid circulation. An integrated plate-fin type heat exchanger has been designed to obtain good compacity and to reach high absorption/desorption rates. At first, the storage system has been tested in accordance with project specifications (absorption/desorption 3.5/1.5 bar). Then, the hydrogen charge/discharge times have been decreased to reach system limits.

System design has also been modelled in order to simulate thermal and mass behaviour of the storage tank. The model is based on Fluent software. We take into account heat and mass transfers in the porous media and a convective flow required to cool/heat the system during absorptions/desorptions. The thermal and mass behaviour of the hydride has been integrated in the software.

The heat and mass transfers experimentally obtained have been compared to results calculated by the model.

Keywords: Hydrogen; Storage; Hydride

\section{Introduction}

Hydrogen storage represents a technological challenge to be solved for a commercial development of energy converters using hydrogen. Among the different hydrogen storage means (compressed gas, liquid hydrogen, adsorption and absorption in solids) reversible metal hydrides (MHs) are considered as a safe and volume efficient hydrogen storage medium, offering low pressure and high energy density. In the present work, an MH buffer tank will be used in combination with a hydrogen production unit to supply a $40 \mathrm{~kW}$ stationary proton exchange membrane fuel cell (PEMFC). The production unit will provide hydrogen gas at a pressure of 3.5 bar while the fuel cell is

\footnotetext{
* Corresponding author.

E-mail addresses: maxime.botzung@cea.fr (M. Botzung), michel.latroche@glvt-cnrs.fr (M. Latroche), philippe.marty@cea.fr (P. Marty).
}

supplied with gas at 1.5 bar. In between, the storage tank will be used as a buffer working at an average temperature of $75^{\circ} \mathrm{C}$. For this study, $\mathrm{LaNi}_{5}$ substituted derivatives ( $\mathrm{AB}_{5}$-type compounds) were chosen as hydrogen storage materials to reach the needs of this specific application.

The aim of this study is to test an MH tank based on plate-fin technology. The results of these tests will validate a numerical tool able to simulate the behaviour of the $\mathrm{MH}$ tank.

\section{Presentation}

Fig. 1 shows a combined heat and power (CHP) system providing $40 \mathrm{~kW}$ electric power. The system includes a hydrogen production unit using methane reforming, a PEMFC and a hydrogen storage unit using MHs.

Specifications of the project impose some requirements for the storage device: reversible storage capacity, operating 


\section{Nomenclature}

$\begin{array}{ll}\frac{\mathrm{d} n}{\mathrm{~d} t} & \text { kinetics of the adsorption reaction, } \mathrm{mol} \mathrm{kg}^{-1} \mathrm{~s}^{-1} \\ E_{\mathrm{f}} & \text { energy of the fluid phase, } \mathrm{J} \\ E_{\mathrm{S}} & \text { energy of the solid phase, } \mathrm{J} \\ F & \text { force vector, } \mathrm{N} \\ \Delta H & \text { enthalpy of the adsorption reaction, } \mathrm{J} \mathrm{mol}^{-1} \\ k_{\mathrm{eff}} & \text { effective conductivity of the packed bed, } \\ & \mathrm{W} \mathrm{m} \mathrm{K}^{-1} \mathrm{~K}^{-1} \\ k_{\mathrm{f}} & \text { thermal conductivity of the fluid, } \mathrm{W} \mathrm{m}^{-1} \mathrm{~K}^{-1} \\ k_{\mathrm{s}} & \text { thermal conductivity of the solid, } \mathrm{W} \mathrm{m}^{-1} \mathrm{~K}^{-1} \\ \mathrm{NL} & \text { volume expressed in litre under standard } \\ & \text { conditions }\end{array}$

$\begin{array}{ll}M_{\mathrm{H}_{2}} & \text { atomic mass of hydrogen, } \mathrm{kg} \mathrm{mol}^{-1} \\ n & \text { specific amount of adsorbed molecule, } \mathrm{mol} \mathrm{kg}^{-1} \\ p & \text { static pressure of the fluid, Pa } \\ S_{\mathrm{h}} & \text { source of heat, } \mathrm{W} \mathrm{m}^{-3} \\ S_{\mathrm{m}} & \text { source of mass, } \mathrm{kg} \mathrm{m}^{-3} \mathrm{~s}^{-1} \\ \vec{v} & \text { overall velocity vector, } \mathrm{m} \mathrm{s}^{-1}\end{array}$

\section{Greek letters}

$\alpha \quad$ permeability, $\mathrm{m}^{2}$

$\varepsilon \quad$ porosity of the packed bed

$\mu \quad$ dynamic viscosity, $\mathrm{Pa}$ s

$\rho_{\mathrm{s}} \quad$ density of the solid phase, $\mathrm{kg} \mathrm{m}^{-3}$

$\rho_{\mathrm{f}} \quad$ density of the fluid phase, $\mathrm{kg} \mathrm{m}^{-3}$

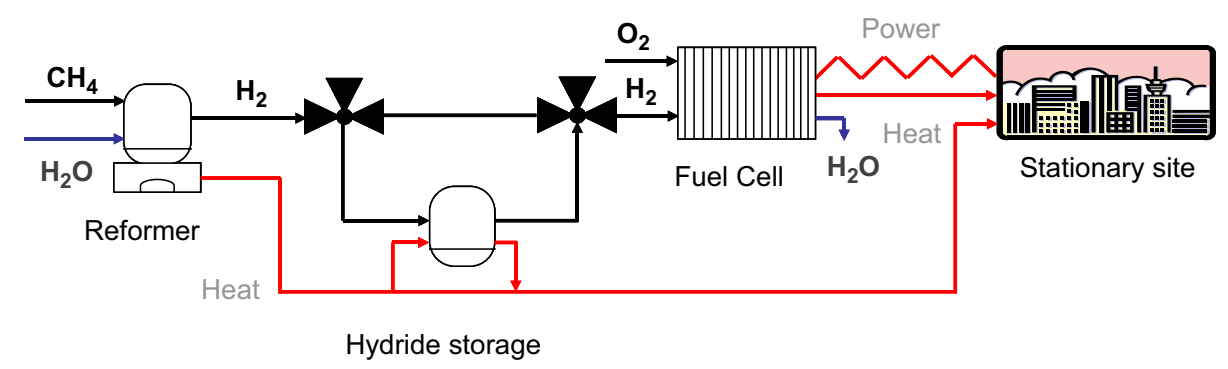

Fig. 1. The combined heat and power (CHP) system in which a hydride tank is necessary.

temperatures and pressures ranges, kinetics, cycling behaviour and material cost. The methane reformer delivers a hydrogen pressure of 3.5 bar while the used fuel cell operates at 1.5 bar.

The hydrogen consumption varies according to the energy demand of the user. Therefore a hydrogen buffer tank is needed to store the excess hydrogen produced during low consumption periods and to deliver it during high consumption periods.

Consequently, the absorption/desorption pressures of the hydride contained in the tank must be between those limits at $75^{\circ} \mathrm{C}$ (working temperature of the fuel cell).

The design of the CHP system requires $5 \mathrm{~kg}$ of hydrogen stored but in a first step, only a $0.1 \mathrm{~kg}$ prototype has been built and tested. According to the weight capacity of the alloy, the tank thus contains $10 \mathrm{~kg}$ of hydride.

The MH tank must fulfil the following conditions:

- Storage of $1.12 \mathrm{Nm}^{3} \mathrm{H}_{2}(100 \mathrm{~g})$ in $10 \mathrm{~kg}$ of $\mathrm{MH}$.

- Absorption in $15 \mathrm{~h}$ with 3.5 bar (flow rate $\mathrm{H}_{2}: 75 \mathrm{NL} \mathrm{h}^{-1}$ ) at $75^{\circ} \mathrm{C}$.

- Desorption in $9 \mathrm{~h}$ with 1.5 bar (flow rate $\mathrm{H}_{2}: 125 \mathrm{NLh}^{-1}$ ) at $75^{\circ} \mathrm{C}$.

The study of $\mathrm{AB}_{5}$ compounds [1] led to the development of a new composition adapted to the project needs. The hydride composition is $\mathrm{La}_{0.90} \mathrm{Ce}_{0.05} \mathrm{Nd}_{0.04} \mathrm{Pr}_{0.01} \mathrm{Ni}_{4.63} \mathrm{Sn}_{0.32}$. The absorption and desorption pressures of the hydride at $75^{\circ} \mathrm{C}$ ( 2 and 1.85 bar, respectively) are the most adapted to the specifications. The reversible storage capacity $(0.95 \mathrm{wt} \%)$ has been optimized for our working conditions.

Once the MH was chosen, a system able to contain the metal powder has been designed in order to obtain efficient kinetics and adapted mechanical strength.

\section{Design of the MH tank}

To decrease the hydrogen charging/discharging time, the heat exchange has to be efficient. A rectangular design (Fig. 2) has been chosen to obtain a good compacity with an integrated plate-fin type heat exchanger coupled with the use of aluminium foam.

This structure may be easily disassembled so there is an addition of weight and volume.

The various components of the plate-fin type MH tank are shown in Fig. 3. The metallic powder is filled into the "MH Vessel" with aluminium fins and aluminium foam to improve the heat transfer. The heat exchanger and the MH vessel have been made with aluminium according to its good thermal conductivity.

The coolant flows from "inlet of oil" to "outlet of oil" through 12 square cooling channels $(8 \mathrm{~mm} \times 8 \mathrm{~mm})$ in the heat exchanger situated at the base of the MH tank.

A plate "stainless steel filter" has been introduced in the MH tank above the powder bed. This filter avoids MH transfer into hydrogen pipes (inlet/outlet of hydrogen) and prevents the powder from moving inside the tank. The MH tank can be moved 
and can be subjected to vibrations (like vibration occurring inside a car). In addition, the pressure drop of hydrogen within the $\mathrm{MH}$ powder layer is reduced because of the small $\mathrm{MH}$ layer (35 mm).

The heat transfer characteristics in the MH are measured with thermocouples. The stainless steel cover integrates six probes made of three thermocouples each to measure the temperature at three levels inside the MH bed (see Fig. 4 for location of the thermocouples). The data from the thermocouples have been

\begin{tabular}{|c|c|}
\hline Effective Storage & 1.2 \\
\hline capacity $\left(\mathrm{Nm}^{3}\right)$ & $(106 \mathrm{~g})$ \\
\hline MH weight (kg) & 10.310 \\
\hline Total weight (kg) & 54.1 \\
\hline External Size (mm) & $480 \times 280 \times 116$ \\
\hline Volume of MH (L) & 2.4 \\
\hline Volume of tank (L) & 15.6 \\
\hline
\end{tabular}

Fig. 2. Information about the rectangular hydrogen storage system build. used to understand and to compare with the numerical model of the heat transfer in the storage system.

Another effect to be taken into account is the powder volume expansion during hydrogen absorption. When hydrogen reacts with the alloy, it occupies crystallographic intersticial sites within the cell leading to an expansion of the metallic matrix (Fig. 5).

According to [1], the metallic powder can expand $12 \%$ of its initial volume. If the expansion effect is not taken into account, it may generate stress which can cause damages on the $\mathrm{MH}$ tank. In order to limit the stress in the tank, a void space has been designed. This void space represents $20 \%$ of the total metal powder volume (Fig. 5).

To limit the stress generated by expansion during hydrogenation, the powder has been introduced into a structure made of aluminium fins which acts as sub-containers, supporting part of the stress due to powder swelling. These fins also improve thermal conductivity through the powder bed.

The filling of the $\mathrm{MH}$ vessel with the $\mathrm{MH}$ powder has been done in a glove box under argon atmosphere in order to avoid contamination of the powder by oxides or humidity.
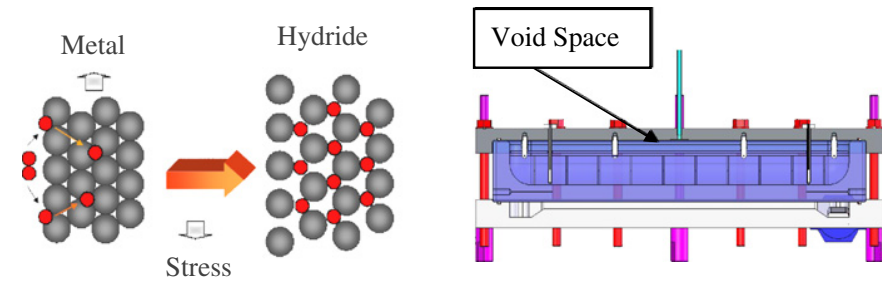

Fig. 5. Expansion of the $\mathrm{MH}$ and void space in the $\mathrm{MH}$ tank.
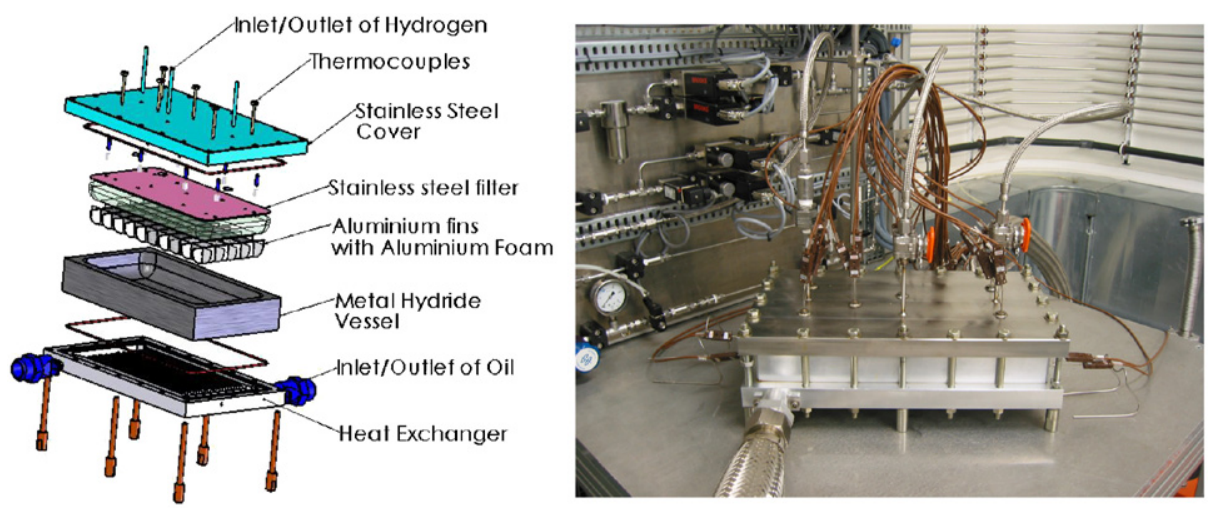

Fig. 3. Exploded view (left) of the MH tank (right).

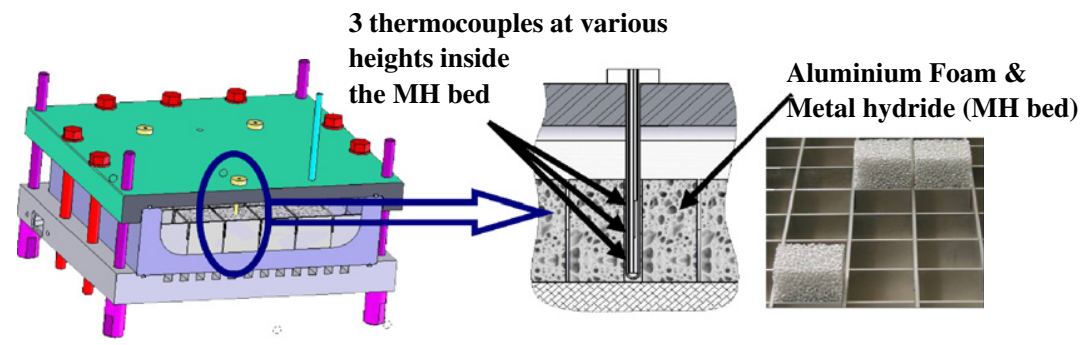

Fig. 4. Repartition of the three thermocouples at different levels inside the MH bed. 
This system has been designed to identify the thermal behaviour of this $\mathrm{MH}$ storage system. The aim is to use the heat from the fuel cell to desorb hydrogen. The heating test bench can simulate the fuel cell behaviour.

\section{Results}

\subsection{Constant flow rate test}

In this section, absorption/desorption characteristics of the MH tank will be given and the heat and mass transfers in the storage vessel will be presented for constant flow rates.

In Fig. 6, the absorption curve for a full charge is shown. The $\mathrm{H}_{2}$ flow rate is fixed at $125 \mathrm{NL} \mathrm{h}^{-1}$. During absorption, the pressure increases from the equilibrium pressure $(0.7$ bar at $65^{\circ} \mathrm{C}$ ) to the set point pressure $(3.5 \mathrm{bar})$. The total $\mathrm{H}_{2}$ uptake is linear during $15 \mathrm{~h} 30$.

The MH tank results with constant flow rate are

- Storage of $1.12 \mathrm{Nm}^{3} \mathrm{H}_{2}(100 \mathrm{~g})$ in $10 \mathrm{~kg}$ of $\mathrm{MH}$.

- Absorption of $1.15 \mathrm{Nm}^{3} \mathrm{H}_{2}(104 \mathrm{~g})$ in $15 \mathrm{~h} 30$ (flow rate: $75 \mathrm{NL} \mathrm{h}^{-1}$ ) at $65^{\circ} \mathrm{C}$.

- Desorption of $1.33 \mathrm{Nm}^{3} \mathrm{H}_{2}(119 \mathrm{~g})$ in $10 \mathrm{~h} 48$ (flow rate: $125 \mathrm{NL} \mathrm{h}^{-1}$ ) at $85^{\circ} \mathrm{C}$.

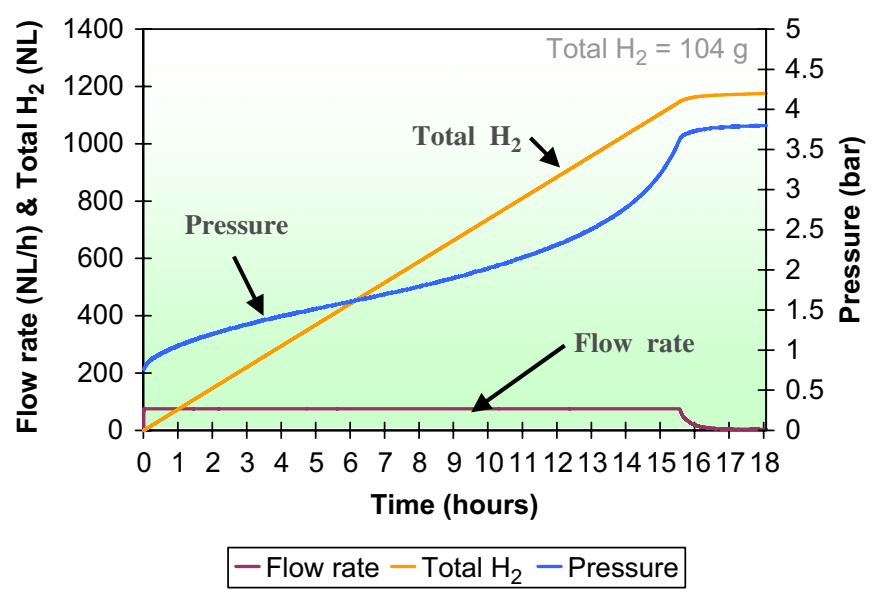

Fig. 6. Absorption cycle with a flow rate of $125 \mathrm{NLh}^{-1} \mathrm{H}_{2}$ (brown), a fluid circulation at $65^{\circ} \mathrm{C}$ and a total $\mathrm{H}_{2}$ uptake of $104 \mathrm{~g}$ (orange).

\subsection{Constant pressure test}

The total absorption/desorption rates are faster when the absorption/desorption pressures are constant and the flow rate varies. Fig. 7 shows the charging characteristics of the plate-fin type $\mathrm{MH}$ tank. The hydrogen supply pressure is fixed at $3.5 \mathrm{bar}$. The cooling fluid rate is set at $10 \mathrm{~m}^{3} \mathrm{~h}^{-1}$ and $20^{\circ} \mathrm{C}$.

For the constant pressure mode, the amount of hydrogen charged (total $\mathrm{H}_{2}$ ) reaches $100 \mathrm{~g}$ of hydrogen in $20 \mathrm{~min}(90 \%$ of the effective storage capacity).

The MH tank results with constants pressures are

- Storage of $1.12 \mathrm{Nm}^{3} \mathrm{H}_{2}(100 \mathrm{~g})$ in $10 \mathrm{~kg}$.

- Absorption in $20 \mathrm{~min}$ (pressure: 3.5 bar) at $20^{\circ} \mathrm{C}$.

- Desorption in $1 \mathrm{~h} 50$ (pressure: 1.5 bar) at $75^{\circ} \mathrm{C}$.

The temperature of the coolant and the different temperatures of the thermocouples in the $\mathrm{MH}$ bed during absorption are given in Fig. 7. These temperatures are measured in the centre of the system (ring in Fig. 4).

During the first step of absorption, a strong increase of temperature is observed in the $\mathrm{MH}$ bed. Once the set point pressure has been reached ( 3.5 bar), the temperature starts to decrease down to the cooling fluid temperature.

\section{Simulation}

During the last years, many studies were made to simulate the thermal and mass transfers in $\mathrm{MH}$ storage systems. Most of them have been done on a two-dimensional axisymmetric model $[2,3]$. Some simulations were made on a threedimensional model $[4,5]$ but these models have been done only on a small section of the MH storage system. This small section does not include the border effects.

In this study, we present results on a three-dimensional model, taking into account the border effects, which represent a quarter of the experimental system (two planes of symmetry) with a total amount of $115 \mathrm{~g}$ of hydrogen stored.

\subsection{The mass conservation equation}

To simulate the absorption/desorption cycle, a compressible $\mathrm{H}_{2}$ flow has been taken into account with the continuity
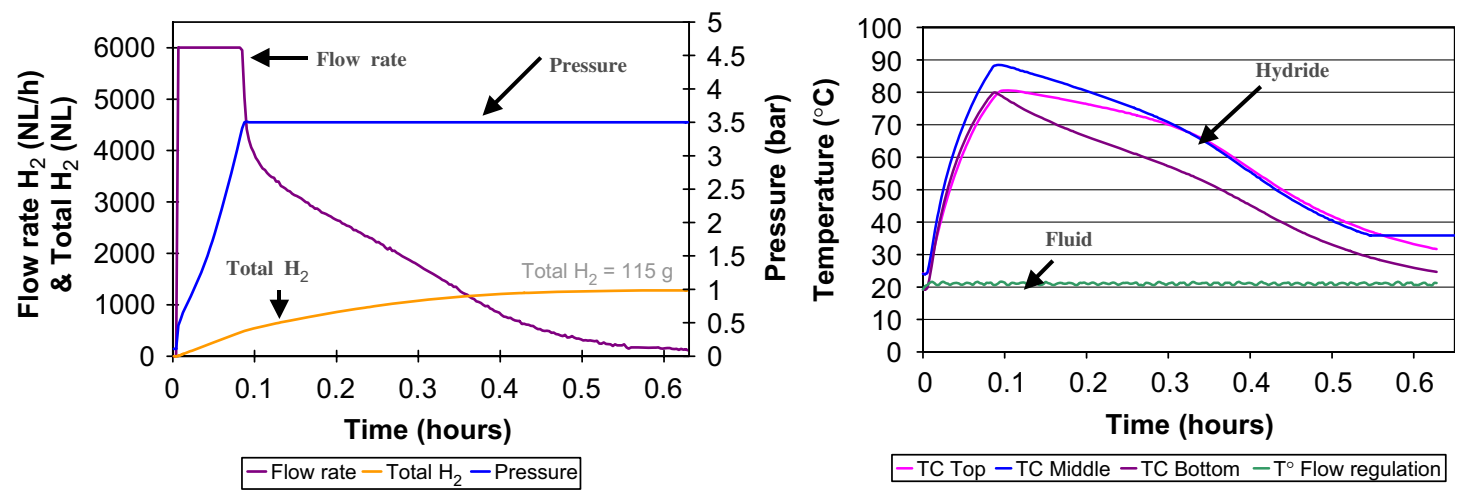

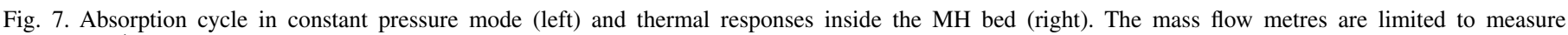
$6000 \mathrm{NL} \mathrm{h}^{-1}$. 
equation associated with a mass source term which is negative during absorption and positive during desorption.

The time-dependent mass conservation equation for the hydrogen flow in an adsorbent porous bed may be written as

$\frac{\partial \rho_{\mathrm{f}}}{\partial t}+\nabla \cdot\left(\rho_{\mathrm{f}} \vec{v}\right)=S_{\mathrm{m}}$

where $\rho_{\mathrm{f}}$ is the fluid density $\left(\mathrm{kg} \mathrm{m}^{-3}\right), \vec{v}$ is the overall velocity vector of the fluid $\left(\mathrm{m} \mathrm{s}^{-1}\right)$ and $S_{\mathrm{m}}$ is a mass source term $\left(\mathrm{kg} \mathrm{m}^{-3} \mathrm{~s}^{-1}\right)$.

The source term $S_{\mathrm{m}}$ accounts for the rate of hydrogen transfer from gas phase to absorbed phase. This rate may be derived on the basis of an equilibrium assumption using the following equation:

$S_{\mathrm{m}}=-M_{\mathrm{H}_{2}} \rho_{\mathrm{s}}(1-\varepsilon) \frac{\mathrm{d} n}{\mathrm{~d} t}$,

where $M_{\mathrm{H}_{2}}$ is the atomic mass of hydrogen and $\varepsilon$ is the porosity of the packed powder bed, $\rho_{\mathrm{s}}=8400 \mathrm{~kg} \mathrm{~m}^{-3}$ the density of the solid phase and $\frac{\mathrm{d} n}{\mathrm{~d} t}$ the kinetics of the absorption reaction $\left(\mathrm{mol} \mathrm{kg}^{-1} \mathrm{~s}^{-1}\right)$.

\subsection{The momentum equation}

The momentum conservation equations with the addition of a momentum source term have been used to model gas flow in a porous media as a standard fluid flow equation. The time-dependent momentum transport equation is similar to the one used for classical homogenous porous media. It may be written as

$\frac{\partial\left(\rho_{\mathrm{f}} \vec{v}\right)}{\partial t}+\nabla \cdot\left(\rho_{\mathrm{f}} \vec{v} \vec{v}\right)=-\nabla p+\nabla \cdot(\overline{\bar{\tau}})+\vec{F}$,

where $\rho_{\mathrm{f}}$ is the fluid density, $p$ the static pressure, $\vec{v}$ the velocity vector $\left(\mathrm{m} \mathrm{s}^{-1}\right), \overline{\bar{\tau}}$ the stress tensor and $\vec{F}$ represents an additional friction term due to the porous medium. This source term accounts for the interactions between the flowing gas and the solid porous medium and it is composed of two parts: a viscous loss term (Darcy) and an inertial loss term due to the strong geometrical variation of the flow lines at the pore scale. In laminar flows through porous media, the pressure drop is typically proportional to velocity and the inertial loss term can be considered to be zero. Ignoring convective acceleration and diffusion, the porous media model then reduces to Darcy's law:

$\vec{F}=-\frac{\mu}{\alpha} \vec{v}$,

where $\mu=8.411 \times 10^{-6} \mathrm{~Pa}$ s is the viscosity of the fluid, $\alpha=$ $1.2 \times 10^{-11} \mathrm{~m}^{2}$ is the permeability of the porous media.

\subsection{The energy balance}

The energy balance equation is similar to those classically used to describe flows in porous media. It includes however a source term that accounts for the energy release during absorption process. This equation assumes that the solid and fluid media are homogeneous, and in particular that their energy and conductivity are modelled by a mixture law. The equation may be written as

$$
\begin{aligned}
& \frac{\partial}{\partial t}\left(\varepsilon \rho_{\mathrm{f}} E_{\mathrm{f}}+(1-\varepsilon) \rho_{\mathrm{s}} E_{\mathrm{s}}\right)+\nabla \cdot\left(\vec{v}\left(\rho_{\mathrm{f}} E_{\mathrm{f}}+p\right)\right) \\
& \quad=\nabla \cdot\left[k_{\mathrm{eff}} \nabla T\right]+S_{\mathrm{h}} .
\end{aligned}
$$

In this equation,

$E_{\mathrm{f}}=h-\frac{p}{\rho}+\frac{v^{2}}{2}$ and $E_{\mathrm{s}}=h$.

For a perfect gas: $h=\int_{T_{\text {ref }}}^{T} C_{\mathrm{P}} \mathrm{d} t$ and $T_{\text {ref }}$ is $298.15 \mathrm{~K}$.

$\varepsilon=0.5$ is the porosity of the packed powder bed, $\rho_{\mathrm{f}}$ is the fluid density, $\rho_{\mathrm{s}}$ the solid density, $E_{\mathrm{f}}$ the energy of the fluid, $E_{\mathrm{s}}$ the energy of the solid powder, $\vec{v}$ the overall velocity vector of the fluid, $p$ the static pressure of the fluid and $k_{\text {eff }}$ is the effective thermal conductivity of the medium. The term $\varepsilon \rho_{\mathrm{f}} E_{\mathrm{f}}+(1-$ ع) $\rho_{\mathrm{S}} E_{\mathrm{S}}$ is a mixture law between the energy contained in the fluid and the energy contained in the solid.

The energy equation is used with an energy source term which is exothermic during absorption and endothermic during desorption.

$S_{\mathrm{h}}= \pm \Delta H \cdot S_{\mathrm{m}}$

where $\Delta H=36000 \mathrm{~J} \mathrm{~mol}^{-1}$ is the enthalpy of the absorption reaction.

The effective thermal conductivity in the porous medium is computed as the volume average of the fluid (hydrogen) conductivity and the solid (metal powder) conductivity. Porosity is considered constant and equal to 0.5 .

It may therefore be expressed as function of the solid and gas conductivities and the porosity (mixture law):

$k_{\mathrm{eff}}=\varepsilon k_{\mathrm{f}}+(1-\varepsilon) k_{\mathrm{s}}$,

where $k_{\mathrm{f}}=0.18 \mathrm{~W} \mathrm{~m}^{-1} \mathrm{~K}^{-1}$ represents the thermal conductivity of the fluid and $k_{\mathrm{s}}=0.5$ is the thermal conductivity of the $\mathrm{MH}$ powder ( $\mathrm{MH}$ powder with aluminium foam $\left.k_{\mathrm{s}}=2\right)$.

\subsection{The coolant}

To regulate the temperature during absorption, a cooling fluid in the square pipes is modelled with a heat exchange coefficient. For a fluid regulation of $10 \mathrm{~m}^{3} \mathrm{~h}^{-1}$ at $293 \mathrm{~K}$, we can consider the coolant like a laminar flow in short channels and the Schlünder correlation [6] advises to consider a $600 \mathrm{~W} \mathrm{~m}^{-2} \mathrm{~K}^{-1}$ heat flux.

\subsection{The hydride behaviour}

In order to simulate the thermal and $\mathrm{H}_{2}$ flow rate behaviour of the tank, the thermal and mass behaviour of the hydride have to be integrated in FLUENT software.

Under isothermal conditions, MHs follow the pressurecomposition behaviour of a phase change. Fig. 8 provides an illustration of this relationship for a decomposition of an $\mathrm{MH}$. Composition (wt $\%$ ) is plotted on the $x$-axis and pressure is 
plotted on a logarithmic scale on the $y$-axis. At a given temperature $\left(25,65,75\right.$ or $85^{\circ} \mathrm{C}$ plotted), the $\mathrm{MH}\left(\mathrm{MmNi}_{5-x} \mathrm{Sn}_{x}\right.$ type) will absorb or release hydrogen along an equilibrium pressure $\left(P_{\mathrm{eq}}\right)$, with a sharp decrease in pressure at low compositions and a sharp increase at high compositions.

Named as a pressure-composition-isotherm (PCI) curve, this plot is commonly used to illustrate the thermodynamic behaviour of an $\mathrm{MH}$.

The analytical expression (PONS model) shown below has been used to simulate the PCI curves. Fig. 8 shows the accuracy obtained between experiments at $25,65,75$ and $85^{\circ} \mathrm{C}$ and the analytical expression [6].

$$
\begin{aligned}
(H / M)^{\prime} & =H / M-h / m, \\
\ln P_{\mathrm{eq}}= & A-\frac{B}{T_{\mathrm{h}}}+C \cdot(H / M)^{\prime}+D \cdot\left[\tan \left(\frac{\pi}{2} \frac{(H / M)^{\prime}}{(H / M)_{\max }^{\prime}}\right)\right]^{n} \\
& +E \cdot\left[\tan \left(\frac{\pi}{2} \frac{(H / M)^{\prime}}{(H / M)_{\max }^{\prime}}\right)\right]^{-m},
\end{aligned}
$$

where $A, B, C, D, E, n, m, \mathrm{~h} / \mathrm{m},(H / M)_{\max }^{\prime}$ are constants, $P_{\mathrm{eq}}$ the equilibrium pressure. $T_{\mathrm{h}}$ is the hydride temperature and $H / M$ is the hydrogen on metal ratio (\% weight on Fig. 8).

In order to charge an $\mathrm{MH}$, hydrogen pressure must be supplied above the equilibrium pressure $\left(P_{\mathrm{eq}}\right)$ at a given temperature. Likewise, hydrogen gas liberated from a metal can only be supplied at or below the equilibrium pressure. The rate

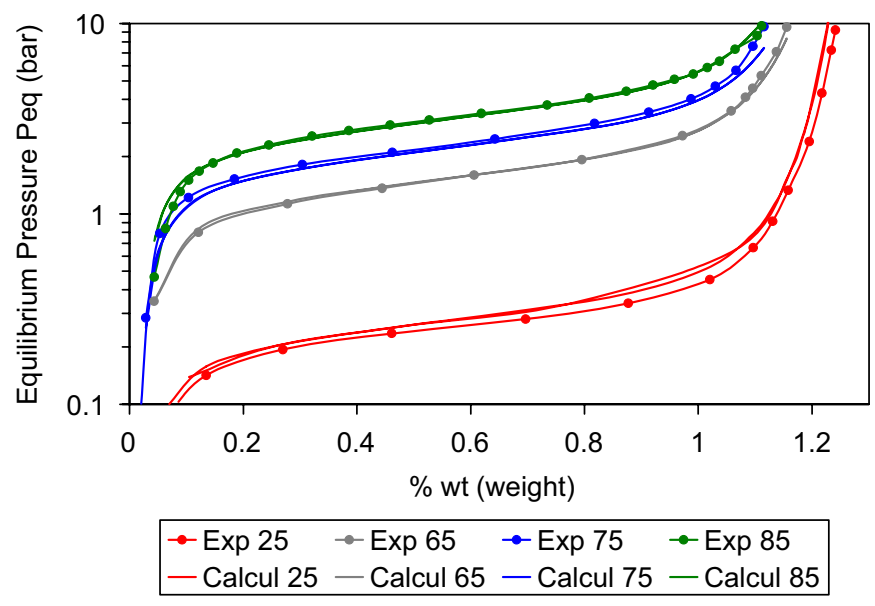

Fig. 8. PCI curves of the hydride $\mathrm{MmNi}_{5-x} \mathrm{Sn}_{x}$ at $25,65,75$ and $85^{\circ} \mathrm{C}$. of reaction is commensurate with temperature and the difference between hydrogen pressure and equilibrium pressure. Therefore, charging and discharging kinetics is dependant on both the temperature and the hydrogen pressure.

A derivate form of the analytical expression given in [2] has been used to simulate thermal and mass kinetics during absorption:

$$
\frac{\mathrm{d} n}{\mathrm{~d} t}=C_{\mathrm{a}} \exp \left(\frac{-E_{\mathrm{a}}}{R \cdot T_{\mathrm{h}}}\right) \ln \left(\frac{P_{\mathrm{H}_{2}}}{P_{\mathrm{eq}}}\right),
$$

where $C_{\mathrm{a}}$ and $E_{\mathrm{a}}$ are absorption constants.

$T_{\mathrm{h}}$ is the hydride temperature, $P_{\mathrm{H}_{2}}$ is the current hydrogen pressure and $P_{\mathrm{eq}}$ is the equilibrium pressure from PCI curves.

\section{Meshing}

The geometry of the tank has been integrated in the FLUENT software from SolidWorks and the MH behaviour has been integrated in the numerical tool.

Fig. 9 describes the computational domain and the boundary conditions. We take into account the quarter of the overall system because there are two symmetry planes. The coolant is modelled by a heat exchange coefficient applied on each surfaces of the cooling channels. We have two different computational domains, one with the $\mathrm{MH}$ with aluminium foam between the aluminium fins. The other domain includes only $\mathrm{MH}$ powder in the rounded sides near to the external adiabatic walls.

At the beginning of the absorption, the system is at $293 \mathrm{~K}$ and the hydrogen is injected at the top of the system, then the hydride absorbs and the exothermic reaction raises the temperature.

\section{Simulation results}

The simulation results are shown in Fig. 10. The mass transfers of the simulation are in agreement with the experimental results. Indeed, during the constant flow rate $\left(6000 \mathrm{NLh}^{-1}\right)$, there is an increase of pressure inside the system.

When the system reaches the set up pressure ( 3.5 bar), it absorbs hydrogen with a constant pressure and there is a decrease of the flow rate which reaches zero when the absorption is complete.

The temperatures during the absorption are in agreement. There is a quick increase of temperature during the constant
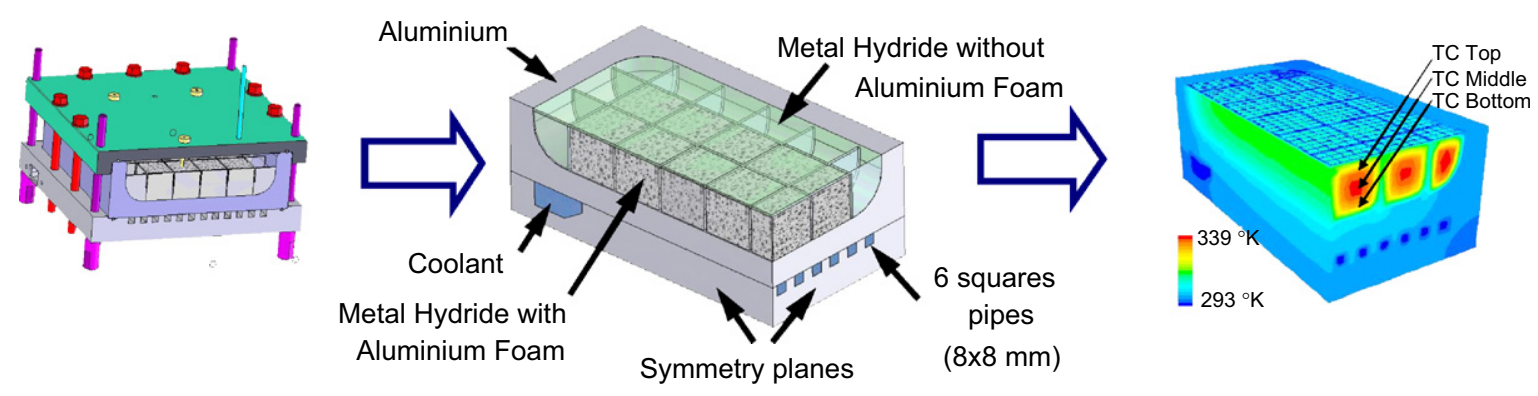

Fig. 9. The facility and its modelled geometry, and contours of temperatures (right) during absorption at $110 \mathrm{~s}\left(\mathrm{H}_{2}\right.$ absorbed $\left.16 \mathrm{~g}\right)$. 

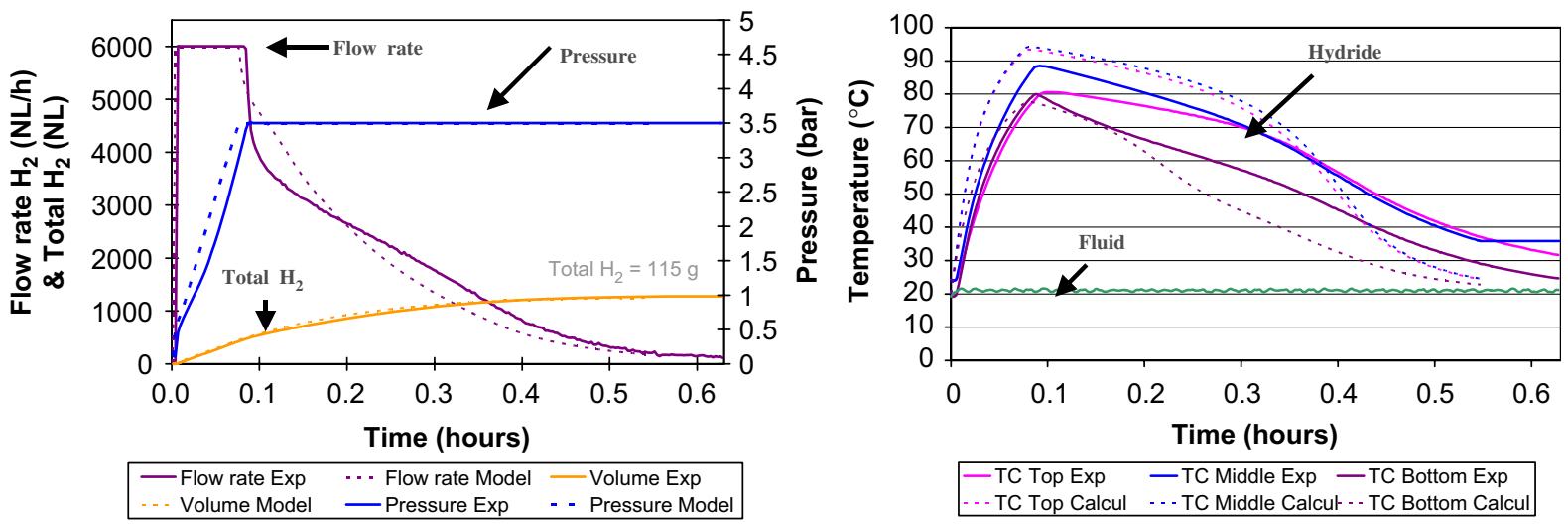

Fig. 10. Experimental results vs numerical results. The experimental results are plotted in continuous lines and the simulation results are plotted in discontinuous lines.

flow rate up to a maximum temperature which corresponds to the set up pressure. Then the flow rate decreases, so the $\mathrm{MH}$ temperatures decrease to the coolant temperature.

\section{Conclusions}

A previous study [1] led to the development of the composition $\mathrm{MmNi}_{5-x} \mathrm{Sn}_{x}$ for which the reversible storage capacity was optimized $(0.95 \mathrm{wt} \%)$ in a narrow pressure range (absorption 3.5 bar, desorption 1.5 bar) at $75^{\circ} \mathrm{C}$.

This metal hydride (MH) has been charged in a plate-fin type MH tank with an effective storage capacity of $1.2 \mathrm{Nm}^{3}(106 \mathrm{~g})$ of hydrogen.

The important characteristics of the MH tank have been analysed and the obtained performances fulfilled the objectives imposed by a stationary cogeneration system.

A numerical tool has been adapted to simulate the thermal and mass behaviour of the hydrogen tank. The simulation is in good agreement with the data obtained from the experiments done with the storage system. This numerical tool will be used to design future $\mathrm{MH}$ storage systems.

\section{References}

[1] Iosub V, Latroche M, Joubert JM, Percheron-Guégan A. Optimisation of $\mathrm{MmNi}_{5-x} \mathrm{Sn}_{x}(\mathrm{Mm}=\mathrm{La}, \mathrm{Ce}, \mathrm{Nd}$ and $\mathrm{Pr}, 0.27<x<0.5)$ compositions as hydrogen storage materials. Int J Hydrogen Energy 2006;31:101-8.

[2] Pons M. Heat transfers in the $\mathrm{LaNi}_{5}$ powder coupled with hydrogenation reaction. Thesis, PARIS VI University; 1991.

[3] Jemni A, Nasrallah SB. Study of two-dimensional heat and mass transfer during absorption in a metal-hydrogen reactor. Int J Hydrogen Energy 1995;20(1):43-52.

[4] Zheng Y, Velagapudi V, Pourpoint T, Fisher TS, Mudawar I, Gore JP. Thermal management analysis of on-board high-pressure metal hydride systems. In: International Mechanical Engineering Congress and Exposition IMECE. Chicago, 2006.

[5] Mosher D, Tang X, Arsenault S, Laube B, Cao M, Brown R, et al. High density hydrogen storage system demonstration using $\mathrm{NaAlH}_{4}$ complex compound hydrides. UTRC, DOE Annual Review, Arlington; 2007.

[6] Shah RK, London AL. Laminar flow forced convection in ducts. New York: Academic Press; 1978. 